\title{
INCIDENCIA DE LA LEY 11/1981 EN MATERIA DE SUCESIONES
}

\author{
Dr. LUIS FERNANDO SAURA
}

Parafraseando el artículo 3,1 del Código Civil, yo diría que las normas no sólo se interpretarán, sino también se elaborarán... en relación con el contexto, antecedentes históricos y legislativos y la realidad social del tiempo en que han de ser aplicadas.

En efecto nada existe tan cambiante y relativo como la norma jurídica, siempre en vigilia como el buho de Minerva, espectador atentísimo de algo para ella, tan significativa y vertiginosamente cambiante cual es la realidad social en cada lugar y en cada tiempo.

De aquí el título genérico del Ciclo de conferencias y mesa redonda que organiza el Colegio de Abogados: "Las leyes reformadoras del Código Civil de 1981: Respuesta legal y pauta informadora del cambio normativo civil".

De aquí también el escogido para esta mi brevísima intervención que, a manera de taracea, pretendo incrustar -para su relieve, participando del mérito ajeno- en la magistral lección que, inmediatamente, impartirá el Profesor Albadalejo.

Manifiesto lo anterior e iniciando la aproximación al tema, considero -como casi todos los que a estos menesteres nos dedicamos- que las reformas del Código Civil de 1981 han sido sólo un hito, un eslabón -aunque de enorme importancia, sin duda- más en esa cadena de modificaciones y adecuaciones de nuestro Código a lo largo de su amplio siglo de existencia. Mas como tiempo y circunstancias imponen límites, quiero destacar, de las anteriores a 1981, únicamente las de 24 de abril de 1958 y la de 2 de mayo de 1975, en tanto marcan la impronta a seguir y desarrollar por las posteriores, como fueron las que nos ocupan y como lo han sido las de incapacitación e instituciones tutelares de 1983, la de adopción de 1987, la de 1990 eliminando espresiones discriminatorias residuales, y como lo serán las que ahora se están debatiendo en Las Cortes en sede de testamentos por ejemplo.

Curiosamente, cuando nos referimos a las reformas de 1981 parece cual si sólo hubieran hecho mella en nosotros las modificaciones específicamente referidas al Derecho de familia, olvidando la significativa y transcendental incursión en materia de sucesiones, reformando -a veces únicamente suprimiendo referencias ya inadecuadas, pero otras produciendo mutaciones radicales mediante el incisivo bisturí que amputa y elimina lo caduco, implantando lo actual y vigente- nada menos que 46 artículos, y suprimiendo tres de ellos en concreto los números 836, 952, 953.

Obviamente la incidencia en el Derecho de sucesiones obtiene su savia nutricia del giro copernicano que, en especial la Ley de 13 de mayo de 1981, imprime al Código Civil en lo referido a relaciones conyugales y paterno-filiales. 
A ambas vertientes nos referimos seguidamente, cotejando lo de antaño con lo de hogaño, sucintamente y sólo en cuanto sea menester para mejor entendimiento de la normativa que nos ampara. De esta suerte, habremos de aludir a hijos y cónyuges, a sucesión testada e intestada.

\section{1.- De las distintas clases de hijos y de su actual igualdad:}

\section{A.- Normativa anterior a la Ley 1111981.}

De manera global podían reducirse a tres las clases de hijos referidos en la legislación anterior a 1981: Legítimos; legitimados; ilegítimos.

Dentro de las dos segundas categorías existían subdivisiones, como veremos, cuyos efectos, relaciones familiares, derechos y nom.inaciones variaban hasta crear en esta última vertiente, un riquísimo rimero de sustantivos, tan cruelmente escogido como exacto -hay que reconocerlo- en su aplicación.

A los hijos legítimos se referían los artículos 108 y siguientes del Código.

A los legitimados algunos otros, de los que, a manera de botón de muestra, transcribimos los siguientes:

Artículo 119.- "Sólo podrán ser legitimados los hijos naturales. Son hijos naturales los nacidos, fuera del matrimonio, de padres que al tiempo de concepción de aquéllos pudieron casarse con dispensa o sin ella".

Artículo 120.- "La legitimación tendrá lugar:

$1^{\circ}$.- Por el subsiguiente matrimonio.

$2^{\circ}$.- Por concesión Real". (El tradicionalmente conocido como Rescripto del Príncipe).

Artículo 122.- "Los legitimados por subsiguiente matrimonio disfrutarán de los mismos derechos que los hijos legítimos".

Artículo 127.- "La legitimación Real dá derecho al legitimado: ....3ํ․- A la porción legitimaria que establece este Código".

Relativamente a los llamados hijos ilegítimos, distinguía el Código entre los naturales y los demás, estableciendo, al respecto:

Artículo 129.- "El hijo natural puede ser reconocido por el padre y la madre conjuntamente, o por uno solo de ellos".

Artículo 134.- "El hijo natural reconocido tiene derecho: "....3‥- A percibir, en su caso, la porción hereditaria que se determina en este Código".

Más que distinta y lastimosa era la suerte de los "llamémosles" hijos ilegítimos ilegítimos, como nos muestra el Artículo 139: "Los hijos ilegítimos en quienes no concurran la condición legal de naturales, sólo tendrán derecho a exigir a sus padres alimentos, conforme al artículo 143".

Junto a los hijos biológicos o de sangre han compartido filialidad -con más o menos equiparación, con más o menos derechos según los tiempos y las costumbres- los llamados hijos adoptivos.

(Es famosa la anécdota sobre la forma de llegar al Código la figura -tan rabiosamente de actualidad en los tiempos que corren- de la adopción. Se cuenta, en efecto, 
que la Comisión de Códigos que redactó el Proyecto de 1851, a p’unto estuvo de relegarla al más absoluto de los olvidos. Sin embargo, a última hora y al decir de García Goyena, salvose de tan triste suerte pues que un vocal, hijo de Andalucía, manifestó que en su tierra se daban algunos casos de ella, si bien bastante raramente).

Olvidando nosotros también tiempos pasados -que aún a pesar de Manrique no siempre fueron mejores- haremos ligera referencia a la adopción tal como regulara la Ley de 4 de julio de 1970.

Como sabemos, distinguía ésta entre adopción plena y menos plena o simple.

Respecto de la primera disponía el Artículo 179: "El hijo adoptivo acupa en la sucesión del adoptante la misma posición que los hijos legítimos, con las siguientes particularidades: $1^{\underline{a}}$.- concurriendo sólo con hijos ilegítimos y tratándose de sucesión testamentaria no podrán percibir por mejora más que el hijo legítimo menos favorecido. $2^{\circ}$.- Si concurrieren con hijos naturales reconocidos, cada uno de éstos no podrá percibir menos porción que el adoptivo. Los adoptantes ocuparán en la sucesión del hijo adoptivo la posición de los padres legítimos. Los parientes por naturaleza no ostentarán derechos por ministerio de la Ley en la herencia del adoptado, sin perjuicio de lo dispuesto en el artículo 812 del Código.

En cuanto a la adopción simple, afirmaba el párrafo final del Artículo 180: "El hijo adoptivo ocupa en la sucesión del adoptante la misma posición que los naturales reconocidos. El adoptante ocupa en la sucesión del hijo adoptivo una posición aquivalente a la del padre natural.

B.- Consideración de los hijos tras la ley de 13 de mayo de 1981.-

Dispone el artículo 39 de nuestra Constitución:

1.- Los poderes públicos aseguran la protección social, económica y jurídica de la familia.

2.- Los poderes públicos aseguran, asimismo, la protección integral de los hijos, iguales éstos ante la Ley, con independencia de su filiación, y de las madres, cualquiera que sea su estado civil.

3.- Los padres deben prestar asistencia de todo orden a los hijos habidos dentro o fuera del matrimonio, durante su minoría de edad y en los demás casos en que legalmente proceda.

4.- Los niños gozarán de la protección prevista en los acuerdos internacionales que velan por sus derechos".

Siguiendo las pautas marcadas por el referido artículo constitucional, por Ley 11/1981 se redactó el artículo 108 del Código Civil, en la forma que se recoge: "la filiación puede tener lugar por naturaleza y por adopción. La filiación por naturaleza puede ser matrimonial o no matrimonial. Es matrimonial cuando el padre y la madre están casados entre sí. La filiación matrimonial y la no matrimonial, así como la adoptiva plena, surten los mismos efectos, conforme a las disposiciones de este Código".

Si bien carece de toda relevancia -al menos en el orden de los alimentos, y de la 
sucesión- la distinta procedencia de los hijos -matrimoniales, no matrimoniales y adoptivos- siguen existiendo reminiscencias de tiempos pasados en nuestro Código. Así, quién no relaciona inmediatamente el anterior artículo 120 referido a la legitimación por subsiguiente matrimonio, con el actual 119, cuando nos dice: "La filiación adquiere el carácter de matrimonial desde la fecha del matrimonio de los progenitores cuando éste tenga lugar con posterioridad al nacimiento del hijo, siempre que el hecho de la filiación quede determinado legalmente conforme a lo dispuesto en la sección siguiente..."

En lo concerniente a adopción, la Ley 21/1987 de 11 de noviembre le da nueva regulación, cuyas líneas básicas podrían resumirse en: a) Acaba con la distinción anterior entre adopción plena y simple; b) confirma la disposición del artículo 108 del Código en su redacción actual llevando a una equiparación total con el resto de los hijos biológicos y condigna inserción plena en la familia adoptante, como lo prueban, entre otros, el artículo 178 del Código Civil en su párrafo primero especialmente, diciendo: "La adopción produce la extinción de los vínculos jurídicos entre el adoptado y su familia anterior..." o el número 4 del artículo 180, al determinar: "La determinación de la filiación que por naturaleza corresponda al adoptado no afectará a la adopción".

Todo ello tiene su reflejo, naturalmente, en lo referido a patria potestad, alimentos, sucesión, etc. como se verá oportunamente.

\section{2.- De los derechos del cónyuge viudo.}

\section{A.- Breve referencia histórica:}

Sabido es que en el derecho germánico, la preocupación en torno al principio de troncalidad, a la permanencia de los bienes en el tronco familiar de procedencia, se traducía en una indisimulada aversión a la sucesión mortis causa en favor del cónyuge viudo, quién, al hacerlos suyos, podía dirigirlos a su propia familia. En la búsqueda de fórmulas conciliatorias entre troncalidad y protección al cónyuge sobreviviente, las más frecuentes eran, ya establecer regímenes económico-matrimoniales con participación en los bienes adquiridos constante matrimonio, ya constituir, en favor del cónyuge viudo, usufructo sobre los bienes.

Tampoco en Derecho romano andaba en exceso beneficiado el cónyuge viudo a la hora de competir con los parientes del premuerto en el reparto de bienes fallecido éste abintestato, siguiéndose en tales eventos, el orden jerárquico siguiente:

$1^{2}$.- Descendientes legítimos tanto del lado paterno como del materno. (En atención a quien fuere el fallecido, lógicamente).

$2^{\mathrm{a}}$ - Ascedendientes paternos y maternos, hermanos y hermanas carnales, y descendientes de estos últimos.

3a.- Hermanos y hermanas consanguíneos, hijos del mismo padre, pero de madres distintas o uterinos y sus descendientes.

4⿳亠丷. - Cognados tanto del lado paterno como del materno. Las Novelas no precisan si existe la limitación al sexto y séptimo grado.

5a.- Las Novelas no hablan de la sucesión del cónyuge cobreviviente que, sin embargo, parece admitida a falta de cognados. (1). 
En la misma línea justinianea, y con su peculiarísimo y entrañable romance, nos dirá la Partida Sexta, Título XIII, Ley Sexta: "...E sobre todo esto dezimos, que si alguno muriesse sin testamento, que non ouiesse parientes, de los que suben o descienden por la liña derecha, nin ouiesse hermano, nin sobrino fijo de su hermano, que destos adelante el pariente que fuere fallado que es mas cercano del defunto hasta en el dezeno grado, esse heredera todos sus bienes. E si tal pariente non fuesse fallado, E el muerto auia muger legitima, quando fino heredara ella todos los bienes de su marido, esso mismo dezimos del marido que heredara los bienes de su muger en tal caso como este. E si por auetura el que assi muriesse sin parientes non fuesse casado, estonce heredara todos sus bienes la camara del Rey". (2).

Entiende Lacruz Berdejo (3) estable la situación que hemos dejado expuesta, hasta la Ley de Mostrencos que coloca, dice, al viudo después del cuarto grado de la línea colateral, con una reserva de los bienes raices de abolengo.

Señala Díez-Picazo, a este propósito, que reiterada jurisprudencia del T.S. iniciada en 1893 y sostenida hasta 1958, se decantaba en pro del entendimiento de haber sido derogado el derecho especial de los territorios forales por la referida Ley de Mostrencos, y que, por consecuencia, en cuanto vino el Código a sustituir a meritada Ley, establecía un régimen unitario para todos, en sede de sucesión intestada. Argumento endeble para Diez-Picazo en tanto que si bien la Ley de Mostrencos tenía carácter general en alguno de los llamamientos sucesorios abintestato que hacía -fundamentalmente el del Estado- dejaba intacta el resto del contenido de la institución. Termina el autor señalando la superfluidad acual de la discusión, tras la aparición de las Compilaciones de los Derechos Civiles especiales, confirmando la subsistencia de normas forales relativas a este tipo de sucesión.(4).

En todo caso, lo que es innegable es que el Código Civil mejoró sensiblemente la situación del cónyuge viudo, al concederle -en su versión inicial 1888-1889- unos considerables derechos legitimarios en concurrencia con hermanos del causante; y en la sucesión intestada a falta de hermanos o sobrinos hijos de tales hermanos del cónyuge fallecido, una posición que, si nó envidiable, mejoraba manifiestamente la que ocupaba antes.

\section{3.- Factores básicos del cambio normativo.}

Tras la lectura del artículo 14 de la Constitución: "Los españoles son iguales ante la Ley, sin que puede prevalecer discriminación alguna por razón de nacimiento, raza, sexo, religión, opinión, o cualquier otra condición o circunstancia personal o social.

$\mathrm{Si}$, seguidamente, espigamos algunos párrafos del ya citado artículo 39 de la Constitución, como, por ejemplo:"...Los poderes públicos aseguran, asimismo, la protección integral de los hijos, iguales éstos ante la Ley con independencia de su filiación..." "Los padres deben prestar asistencia de todo orden a los hijos habidos dentro o fuera del matrimonio..."

¿Era posible redactar de forma distinta a cómo se ha realizado por ley 11/1981 el artículo 108 del Código Civil, sin infringir paladinamente la Constitución?. 
Siendo evidente que la Constitución se limitó, en este punto, a recoger un clamor popular en favor de los seres más indefensos, aquellos fruto de un capricho, de un deseo, traidos sin su anuencia y en tantas ocasiones abocados al desamparado, a una existencia miserable.

Relativamente al cónyuge, apunta del propio modo atinadamente Lacruz Berdejo, (5) la ampliación de derechos ahora concedida por el legislador al mismo desde la reforma de 1981, se inscribe en la línea de creciente conyugalidad y reducción de la familia (familia nuclear) en la cual los lazos de afectos son, en principio, mayores entre los cónyuges que entre los hermanos. (Afirmación que, acaso, un tantico radical, encajaría mejor para el habitante de la gran urbe que apenas se relaciona con sus parientes, más que el de los pueblos. Pero -y no converdría echarlo en saco roto- ¿hay mayores rencores, odios y enfrentamientos que aquellos entre hermanos tratándose de herencias?.

Tras lo dicho, sin embargo, queda una especie de sabor amargo, de insatisfacción, de alguna pieza que no encaja en este "puzzle" de la reforma de 13 de mayo de 1981, y así lo pone de manifiesto Torres Lana (6), cuando, bajo el epígrafe "La tensión filiación familia", escribe: "Antes de la reforma, tanto el régimen jurídico de la filiación como el de la familia eran objeto de una regulación de extrema y cuidadosa coherencia. Aunque fueran discutibles algunos de sus presupuesto ideológicos, lo cierto es que su desenvolvimiento práctico tenía lugar en perfecta sincronía... Un correcto planteamiento de la reforma, dentro del ámbito estrictamente técnico hubiera exigido enfrentar, comparar y ponderar los intereses correspondientes a los dos "status" enfretados (hijos-familia) ...Las consecuencias del régimen instaurado sugieren claramente una simple disyuntiva: o quiebras el principio o protección a la familia matrimonial, o se traslada el centro de protección y la propia noción de familia a la biológica o de hecho, criterio este último que pudiera verse propiciado por la redacción del taxto constitucional ...El legislador de la reforma parece haber optado por esta segunda solución: sin embargo, su admisión acrítica no es nada fácil para un jurista...".

\section{De la sucesión forzosa.}

\section{A.- Normativa anterior a 1981.}

Hemos apuntado que uno de los momentos decisivos de la dialéctica modificadora de nuestro Código Civil, fue la Ley de 24 de abril de 1958 Fue, sin duda, el gérmen de la radical transformación sufrida por la normativa civil en sede de familia y sucesiones.

Precisamente ella redacta los artículos en la forma que pasamos a transcribir.

1.- Herederos forzosos. Los eran, a tenor del artículo 807: "1ํ․ Los hijos y descendientes legítimos respecto de sus padres y ascendientes legítimos. $2^{\circ}$. A falta de los anteriores, los padres y ascendientes legítimos respecto de sus hijos y descendientes legítimos. $3^{2}$. El viudo o viuda, los hijos naturales legalmente reconocidos y el padre o madre de éstos, en la forma y medida que establecen los artículos 834 a 842 y 846 . 
(Por razones de espacio, y en tanto se hará referencia a ello con posterioridad, excusamos la transcripción de los artículos que hacían referencia a hijos y descendientes legítimos y a padres y ascendientes también legítimos).

2.- Derechos del cónyuge viudo.

Artículo 834.- El cónyuge que al morir su consorte no se hallare separado o no lo estuviere por culpa del difunto, si concurre a la herencia con hijos o descendientes, tendrá derecho al usufructo del tercio destinado a mejora.

Artículo 835.- Cuando estuvieren los cónyuges separados en virtud de demanda, se esperará al resultado del pleito. Si entre los cónyuges separados hubiere mediado perdón o reconciliación, el sobreviviente conservará sus derechos..

Artículo 836.- En el caso de concurrir hijos de algún matrimonio anterior del causante, el usufructo correspondiente al cónyuge viudo recaerá sobre el tercio de libre disposición. En tal supuesto, si hubiere hijos naturales se adjudicará a éstos su legítima en nuda propiedad y si, mientras dure el usufructo, estuvieren en el caso de necesitar alimentos, tendrán derecho a exigirlos a todos los legitimarios en proporción a su haber hereditario".

Artículo 837.- No existiendo descendientes pero sí ascendientes, el cónyuge sobreviviente tendrá derecho al usufructo de la mitad de la herencia.

Artículo 838.- No existiendo descendientes ni ascendientes el cónyuge tendrá derecho al usufructo de los dos tercios de la herencia.

3.- De los derechos de los hijos ilegítimos.

Artículo 840.- Cuando el testador deje hijos o descendientes legítimos e hijos naturales legalmente reconocidos, tendrá cada uno de éstos derecho a la mitad de la cuota correspondiente a cada uno de los hijos no mejorados, siempre que quepa dentro del tercio del libre disposición, del cual habrá de sacarse, deduciendo antes los gastos de entierro y funeral. Los hijos legítimos podrán satisfacer la cuota que corresponda a los naturales en dinero o en otros bienes de la herencia a justa regulación".

Artículo 841.- "Cuando el testador no dejare hijos o descendientes pero sí ascendientes legítimos, los hijos naturales reconocidos tendrán derecho a la cuarta parte de la herencia. Esto se entiende sin perjuicio de la legítima del cónyuge viudo, que concurriendo con hijos naturales reconocidos, será un tercio de la herencia en usufructo, que se adjudicará a éstos en nuda propiedad mientras viviere el viudo, lo que les falte para completar la legítima".

Artículo 842.- "Cuando el testador no dejare descendientes ni ascendientes legítimos, los hijos naturales reconocidos tendrán derecho a la tercera parte de la herencia".

Artículo 843.- "Los derechos reconocidos a los hijos naturales en los precedentes artículos se transmiten por muerte a sus descendientes legítimos".

Artículo 844.- La porción legitimaria de los legitimados por concesión Real será la misma establecida por la Ley en favor de los hijos naturales reconocidos".

Artículo 845.- Los hijos ilegítimos que no tengan la calidad de hijos naturales sólo tendrán derecho a los alimentos". 
4.- De los hijos adoptivos.

Damos por reproducido el artículo 179, en su redacción por Ley de 4 de julio de 1970, que trancribimos líneas atrás.

\section{B.- Estado de la cuestión tras la Ley 11/1981.}

1.- Herederos forzosos.

Artículo 807.- Son herederos forzosos: $1^{\circ}$. Los hijos y descendientes, respecto de sus padres y ascendientes. $2^{\circ}$. A falta de los anteriores, los padres y ascendientes respecto de sus hijos y descendientes. $3^{\circ}$. El viudo o viuda en la forma y medida que establece este Código".

Con referencia a la redacción anterior conviene destacar: a) Supresión de toda referencia a legitimidad; b) Asimismo, exclusión de los hijos naturales legalmente reconocidos y de sus padres.

\section{2.- Derechos del cónyuge viudo.}

Persisten, con idéntica redacción, los artículos 834 y 835 .

Se suprimió el artículo 836 , por la razón que se verá al referirnos a los hijos naturales.

Se añade un párrafo segundo al artículo 837, del tenor siguiente: "Igual extensión tendrá el usufructo cuando los únicos herederos forzosos que concurran con el viudo o viuda sean hijos sólo de su consorte concebidos constante el matrimonio de ambos. La cuota usufructuaria recaerá en este caso sobre el tercio de mejora, gravando el resto el tercio de libre disposición".

No se produce modificación alguna en el artículo 838 ya transcrito, ni en el siguiente que pasamos a plasmar:

Artículos 839.- Los herederos podrán satisfacer al cóyuge su parte de usufructo asignándole una renta vitalícia, los productos de determinados bienes, o un capital en efectivo, procediendo de común acuerdo, $y$, en su defecto, por virtud de mandato judicial. Mientras esto no se realice estarán afectos todos los bienes de la herencia al pago de la parte de usufructo que corresponda al cónyuge".

Por último, el artículo 840 que venía a ser el primero de los dedicados a los derechos hereditarios de los hijos naturales legalmente reconocidos, es ahora el que cierra los dedicados a los del cónyuge viudo, disponiendo: "Cuando se esté en el caso previsto por el párrafo segundo del artículo 837, el cónyuge podrá exigir que el usufructo que grave la parte que reciban los hijos le sea satisfecho, a elección de éstos, asignándole un capital en dinero o un lote de bienes hereditarios".

Lo escrito en párrafos anteriores sugiere una serie de reflexiones que interesa anotar:

a.- Es incomprensible la inalteración del artículo 834 en tanto confiere derechos hereditarios al cónyuge inocente y priva de ellos al culpable de la separación, siendo así que, a la luz de la normativa actual, si, ciertamente, existen causas de separación imputables a una sólo de los cónyuges, ni el texto legal conduce a tan radicales consecuencias, ni Juzgado o Tribunal alguno desde la vigencia de las reformas de 1981 
se ha pronunciado nunca sobre la inocencia o culpabilidad de los litigantes para sancionarle con tal medida.

Únicamente podría citarse el caso -y desde luego muy alejado en sus consecuencias a la que nos ocupan- del artículo 95, párrafo segundo del Código, diciendo: "Si la sentencia de nulidad declara la mala fe de uno solo de los cónyuges, el que hubiera obrado de buena fe podrá optar por aplicar en la liquidación del régimen económico matrimonial las disposiciones relativas al régimen de paticipación y el de la mala fe no tendrá derecho a participar en las ganancias obtenidas por su consorte".

En concordancia con ello, había también de dejarse incólume el artículo 835, disponiendo en su párrafo primero: "Cuando estuvieren los cónyuges separados en virtud de demanda, se esperará al resultado del pleito". Elemental, si la sentencia declaraba la culpabilidad del difunto conservaría el cónyuge supérstite sus derechos; y al contrario. supuesto el del artículo 835 que seguramente no se dará en exceso en la práctica, pues, fallecido uno de los litigantes, el Juez, con suspensión del procedimiento, llamará a sus herederos a mantener sus acciones o excepciones; lo que -por no extendernos más en tema que, por otra parte, merecía un trabajo minucioso y asaz interesante- resultaría no sólo diabólico, sino un auténtico galimatías procesal en tema de legitimación.

Lo más racional en hipótesis como éstas, hubiera sido la supresión del artículo 834 y la aplicación "mutatis mutandi" a todo tipo de sucesiones, del artículo 945 en su actual redacción.

b.- Tampoco es de fácil inteligencia el agregado párrafo segundo al artículo 837, pues si se parte del principio constitucional de la igualdad de todos los hijos, no se entiende bien porqué unos -los del artículo 837- deben ceder más o recibir menos, que otro, es los del artículo 807).

Puede parecer un dislate por mi parte la aseveración que sigue, pero ¿es posible que el legislador no cayera en la cuenta de que previamente a la división y adjudicación del caudal hereditario hay que proceder a la liquidación de la sociedad de gananciales -si la hubiere, claro-?

Produce la impresión el párrafo que nos ocupa de que, o bien el legislador quiso, de alguna forma, sancionar "el pecado" del cónyuge libertino, o que no quisiera se beneficiaran en la misma medida el hijo de uno solo que los del matrimonio; cual si hubieran de entrar en el mismo saco todos lo bienes habidos durante la convivencia conyugal.

c.- Mientras afirma el artículo 838: "No existiendo descendientes ni ascendientes el cónyuge tendrá derecho al usufructo de los dos tercios de la herencia", dispone el 944: "En defecto de ascendientes y descendientes, y antes que los colaterales, sucederá en todos los bienes del difunto el cónyuge sobreviviente".

Aunque no puede existir confusión alguna sobre tales artículos, no está de más puntualizar que el 838 ser refiere a sucesión testamentaria -y, en efecto, se ha testado- mientras que se incribe el 944 en la intestada.

\section{3.- Pago de la porción hereditaria en casos especiales.}

En su redacción anterior a 1981, la sección $8^{\mathrm{a}}$ del Capítulo II referido a la 
herencia, se inscribía bajo el título "De los derechos de los hijos ilegítimos", y comprendía desde el artículo 840 al 847 , inclusives.

Tras la reforma referida, el artículado quedaba vacío de contenido ante la equiparación, a todos los efectos de los, antaño, diferentes clases de hijos. ante ello la disyuntiva consistía en suprimirlos o encajar en su artículado una nueva normativa. Ésta fue la solución escogida, comenzando por variar el epígrafe, trasladar el artículo 840 a la sección anterior, y rellenar los siguientes, hasta el 847, con nuevas normas armónicamente justificadoras del estrenado encabezamiento de la sección.

Un resumen apresurado, y por tanto incompleto, de las líneas básicas reguladoras de la cuestión, podría exponerse en los puntos que siguen:

a.- Posibilidad de adjudicación, total o parcial, de los bienes hereditarios a alguno de los hijos o descendientes, quien deberá satisfacer, en metálico, su porción hereditaria a los demás legitimarios.

b.- El receptor de los bienes hereditarios, obligado a pagar en metálico la cuota legitimaria a sus hermanos, puede exigir su satisfacción en bienes hereditarios, en cuyo caso se observará lo dispuesto en los artículos 1058 a 1060 del Código.

c.- La partición de que se hace mérito en los dos párrafos anteriores, requiere aprobación judicial, salvo confirmación expresa de todos los legitimarios.

d.- la decisión del pago en metálico deberá ser comunicada a los interesados en el plazo de un año desde la apertura de la sucesión. El pago habrá de realizarse, salvo pacto en contrario, dentro de término de un año máş̧ Los perceptores gozarán de las garantías establecidas en favor del legatario de cantidad. Transcurrido el plazo sin haberse realizado el pago, se precederá al reparto de la herencia conforme a las disposiciones del Código sobre partición.

e.- La fijación del metálico a satisfacer se realizará atendiendo al valor que tengan los bienes al tiempo de la liquidación, habiendo cuenta de los frutos e intereses hasta entonces producidos. Desde la liquidación, devengará el crédito metálico el interés legal.

\section{4.- En torno a preterición.}

A.- Normativa anterior a 1981.

Por disposición del artículo 814 del Código, "la preterición de alguno o de todos los herederos forzosos en línea recta anulará la institución de heredero, pero valdrán las mandas y mejoras en cuanto no sean inoficiosas.

Lo que significaba que la preterición anulaba en todo caso la institución de heredero, de suerte que el instituido perdía totalmente su porción de la herencia. Sin embargo, subsistían mandas y mejoras en tanto no perjudicaran las legítimas.

Si el preterido era el cónyuge viudo, la institución de heredero no se anulaba, conservando el preterido su derecho a la cuota vidual.

Premuriendo al testador los herederos forzosos preteridos, surtía efecto la institución. Sin perjuicio del derecho de representación que, dudosamente, asistiría a los descendientes de los herederos forzosos preteridos; bien en razón de su propio derecho al amparo del artículo 807 del Código Civil en otro caso, o, finalmente al amparo del derecho de sustitución. De suerte que, ni aún en el caso de suponer la preteri- 
ción una desheredación encubierta, perderian sus derechos los hijos o descendientes del preterido respecto a la legítima, no sólo por las razones apuntadas, sino, principalmente, por aplicación del artículo 857 del Código.

\section{B.- Redacción por Ley 11/1981.}

Distingue en la actualidad el artículo 814 entre preterición instencional y no intencional.

a.- Intencional. La preterición no perjudica la legítima, que debe recibir incluso con su porción de mejora, si el tercio de ella no estaba destinada específicamente a beneficiario concreto.

Planteado así el tema, se satisfará la legítima del preterido reduciendo la institución de herederos, y si aún así no se cubriese, seguirán el proceso reductor los legados, las mejoras y las demás disposiciones testamentarias.

b.- No intencional. Formula el artículo 814 las siguientes hipótesis y consecuentes efectos:

$1^{\circ}$.- Preterición de todos los legitimarios; supuesto que anulará las disposiciones testamentarias de contenido patrimonial.

$2^{\circ}$.- Preterición de sólo alguno o algunos de los legitimarios, se sigue la solución clásica de anulación de la institución de herederos, pero valdrán las mandas y mejoras en cuanto no resulten inoficiosas. Sin embargo, la institución de heredero en favor del cónyuge sólo se anulará en cuanto perjudique a las legítimas.

Cuestión interesante es la suscitada por el párrafo 5 del artículo 814 al establecer: "Los descendientes de otro descendiente que no hubiese sido preterido, representan a éste en la herencia del ascendiente y no se consideran preteridos".

Apuntaba Castán (7) que la tradición romanista desarrolló la doctrina de la representación considerándola aplicable, exclusivamente, a la sucesión intestada. Tesis seguida en nuestro derecho sucesorio, siquiera hasta la reforma del Código en 1981.

No obstante, hacía Castán referencia a la existencia de parte de la doctrina mantenedora de tesis ampliatorias, pronunciándose por la aplicación de la figura tanto a la sucesión testada como a la intestada, basándose en argumentos del tenor de algunos de los que recogemos:

a.- El derecho de representación es de aplicación tanto a la sucesión testada como a la legítima, por tratarse de un principio general de la sucesión familiar, como lo prueba el hecho de que el artículo 925 hable de que la representación tendrá lugar en la línea recta descendente siempre; es decir, en cualquier tipo de sucesión.

b.- La posibilidad de representar a persona viva en caso de desheredación, a que se refiere el artículo 929, es también buena demostración de que tal derecho se da en la sucesión testada, pues en la intestada no tiene sentido la desheredación.

De entre los argumentos contrarios a las opiniones expuestas, de taca Castán, sobre todos, los que distinguen entre la sustitución del artículo 744 y la represetación del 924, propia la primera de la sucesión testada, y de la intestada la segunda; citando, algunos valedores de esta postura como Royo Martínez, Lacruz-Sancho, 
Puig Brutau, De la Cámara Álvarez, etc.; y algunas sentencias propiciatorias de la misma, como las de 22 de junio de 1931; 7 de julio de 1950; 7 de junio de 1952; 5 de octubre de 1966, etc.

Para Lacruz-Sancho, por virtud se esta regla introducida en el artículo 814, el derecho de representación se produce en la sucesión testada en favor de quien la tendría igualmente si no hubiera testamento. (8).

También Torres Lana (9) se decanta por considerar la consagración por el precepto de un auténtico derecho de representación aplicable a la sucesión testamentaria, aunque cuida, escrupulosamente, de marcar las diferencias con la represetación regulada en los artículos 924 y siguientes del Código, estableciendo los caracteres diferenciales siguientes:

a.- Mientras en la representación no testamentaria el derecho de representación se extiende a los colaterales (artículos 925, 2, y 927), en la testamentaria se concreta a los descendientes en línea recta, en tanto únicamente se puede preterir a los legitimarios.

b.- El párrafo 5 del artículo 814 se limita al caso de la premoriencia del descendiente no preterido, pues su desheredación e indignidad se da en el artículo 766 que, a su vez, remite a los artículos 761 y 857.

c.- Las consecuencias patrimoniales derivadas del supuesto en estudio son asaz ambíguas y confusas, siendo las únicas hipótesis posibles dada la premoriencia, las siguientes: $1^{\mathrm{a}}$. Que el descendiente premuerto hubiera recibido una atribución patrimonial igual o mayor a su legítima material, supuesto en el que la representación actuaría normalmente, es decir, los herederos del premuerto ocuparían su lugar en la herencia. $2^{\mathrm{a}}$. Que el premuerto hubiere sido mencionado en el testamento pero no hubiera recibido nada, $o$, en todo caso, menos de lo que por legítima de correspondería; hipótesis en la que se conjugarían las reglas de la representación legitimaria deducidas de los artículos 925, 1, y 807,1. Los descendientes del premuerto adquiririan por representación la condición de legitimarios que les permitiría ejercitar la acción del artículo 815 en reclamación del complemento de su legítima estricta. $3^{\mathbf{2}}$. Que el descendiente hubiere sido omitido en el testamento, sin que tal omisión constituyere preterición por haber fallecido con anterioridad al otorgamiento del testamento. No cabe hablar de preterición en tanto no era preterible el hijo omitido, de ello que la omisión de sus descendientes deba resolverse por las reglas generales de representación en la legítima, pero no por la vía del párrafo 5 del artículo 814 .

Precisa Albadalejo el sentido de la preterición manifestando: "Tratándose de haber sido preterido, omitido o silenciado, es decir, de no habérsele dado nada ni inter vivos ni mortis causa, ni habérsele mencionado en el testamento aunque hubiere sido para desheredarlo (incluso injustamente), el legitimario, en defecto de que el testador haya dispuesto algo que respetando las legítimas, regule el caso distintamente... tiene derecho, como regla a que se reduzca primero la institución de heredero, y si aún no suprimida del todo, puede cubrirse la legítima, que se reduzcan a prorrata los legados, mejoras y demás disposiciones testamentarias, hasta lo necesario para cubrirlas.

Tras analizar los distintos supuestos y consecuencias de la llamada preterición 
no intencional, pone Albaladejo el acento en el párrafo 5 del artículo 814, puntualizando que tal precepto da solución al caso en el que sin él resultarían preteridos los descendientes ulteriores del causante que viniesen a ser legitimarios de éste en el puesto de un intermediario que llegase a faltar después del testamento y antes de la muerte del testador, como si viviendo sus hijos, el padre los instituye herederos y premuriéndole luego uno, con lo que pasan a ser legitimarios sus propios hijos en su puesto (nietos del testador), resultaría que éstos, no instituidos en el testamento del abuelo, pero siendo legitimarios de él cuando muere, habrían sido preteridos. Lo que se evita con el precepto en estudio, que les concede, como representantes de su padre, lo dejado en testamento a éste, evitándose así la preterición. (10).

\section{5.- Innovaciones en sede de mejoras.}

A.- Normativa anterior a 1981.

Solamente dos artículos han merecido la atención del legislador de 1981 en tema que nos ocupa, el 823 y el 831 ; ligeramente retocado el primero y más profundamente afectado el segundo.

Disponían, respectivamente, en su redacción de antaño:

Artículo 823: "El padre o la madre podrán disponer a favor de alguno o algunos de sus hijos o descendientes de una de las dos terceras partes destinadas a legítima. Esta porción se llama mejora".

Artículo 831: "No obstante lo dispuesto en el artículo anterior, podrá válidamene pactarse, en capitulaciones matrimoniales, que muriendo intestado uno de los cónyuges, pueda el viudo o viuda que no haya contraido nuevas nupcias, distribuir a su prudente arbitrio, los bienes del difunto y mejorar en ellos a los hijos comunes, sin perjuicio de las legítimas y de las mejoras hechas en vida por el finado".

B.- Modificaciones introducidas por la Ley 11/1981.

a.- Relativamente al artículo 823 , lo más destacable de la reforma es la referencia a hijos o descendientes por naturaleza o adopción.

b.- Más enjundia tiene la modificación del artículo 831, resumible en las notas siguientes:

$1^{\text {a. }}$ - Mientras en la redacción anterior la posibilidad de distribución de los bienes del causante por el cónyuge supérstite se hallaba en fución del fallecimiento abintestato de aquél, en la actual hace expresa referencia a ordenarse por testamento.

$2^{\mathrm{a}}$ - - Si antaño cabía mejorar a los hijos comunes "sin perjuicio de las legítimas y de las mejoras hechas en vida por el finado", subsiste hogaño tal posibilidad, expresada del siguiente modo: "sin perjuicio de las legítimas y de las mejoras y demás disposiciones del causante".

3‥- Se añade al artículo el párrafo que sigue: "Si no se hubiese señalado plazo, el viudo o viuda tendrá el de un año, contado desde la apertura de la sucesión, $o$, en su caso, desde la emancipación de los hijos comunes". 


\section{DE LA SUCESION INTESTADA}

A.- Normativa anterior a la Ley de 13 de mayo de 1981.

1.- Disposiciones generales:

Artículo 912: "La sucesión intestada tiene lugar: $1^{2}$. Cuando uno muere sin testamento, o con testamento nulo, o que haya perdido después su validez..."

Artículo 913: "A falta de herederos testamentarios, la Ley defiere la herencia, según las reglas que se expresarán, a los parientes legítimos y naturales del difunto, al viudo o viuda y al Estado".

2.- Del orden de suceder según la deversidad de líneas:

a.- Sección $2^{\mathrm{a}}$. De la línea recta ascendente:

Dedica el Código a este menester los artículos 935 a 942, inclusive pero, en rigor, pueden ser resumidos en la forma siguiente:

$1^{\text {ạ }}$. El padre y la madre, si existieren, herederán por partes iguales. Si sólo existe uno de ellos, sucederá al hijo en la totalidad de la herencia.

$2^{\mathrm{a}}$.- En defecto de padre y madre sucederán al causante los acendientes más próximos en grado.

3a - Existiendo varios de igual grado y de la misma línea, dividirán la herencia por cabezas. Siendo de igual grado pero pertenecientes a líneas diferentes, corresponderá la mitad de la herencia a los ascendientes paternos y la otra mitad a los maternos, haciéndose, en cada línea, la división por cabezas.

4 ${ }^{a}$ - Para el artículo 938: "Lo dispuesto en los dos artículos anteriores se entiende sin perjuicio de lo ordenado en los artículos 811 y 812 , que es aplicable a la sucesión intestada y a la testamentaria".

Especial interés tenía, en su anterior redacción, el artículo 935, disponiendo: "A falta de hijos y descendientes legítimos del difunto, le heredarán sus ascendientes, con exclusión de los colaterales".

El inciso final era imprescindible para zanjar la acalorada discusión en torno a si habrían de ser preferentes los colaterales o los ascendientes en los derechos sucesorios a la herencia intestada, 0 , según otra postura, si se debía llamar en estos casos conjuntamente a hermanos y ascendientes, dando preferencia a éstos sobre los demás colaterales.

b.- Sección 3a. De los hijos naturales reconocidos.

Artículo 939: "A falta de descendientes y ascendientes legítimos sucederán al difunto en el todo de la herencia los hijos naturales legalmente reconocidos y los legitimados por concesión Real".

Artículo 940: "Si con los hijos naturales o legitimados concurrieren descendientes de otro hijo natural o legitimado que hubiere fallecido, los primeros sucederán por derecho propio y los segundos por representación.

Artículo 941: "Los derechos concedidos al hijo natural o legitimado en los dos anteriores artículos, se transmitirán por su muerte a sus descendientes, quienes heredarán por derechos de representación a su abuelo difunto".

Artículo 942: "En el caso de quedar descendientes o ascendientes legítimos, los 
naturales y legitimados sólo percibirán de la herencia la porción que se les concede en los artículos 840 y $841 "$.

Artículo 943: "El hijo natural y legitimado no tiene derecho a suceder abintestato, a los hijos y parientes legítimos del padre o madre que les haya reconocido, ni ellos al hijo natural ni al legitimado".

Artículo 944: "Si el hijo natural reconocido o legitimado muere sin dejar posteridad legítima reconocida por él, le sucederá por entero el padre o madre que le reconoció y, si los dos le reconociesen y viven, le heredarán por partes iguales".

Artículo 945: "A falta de ascendientes naturales, heredarán al hijo natural y al legitimado sus hermanos naturales, según las reglas establecidas por los hermanos legítimos".

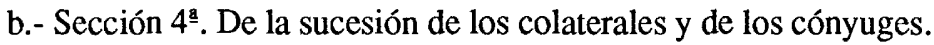

Artículo 946: "A falta de las personas comprendidas en las tres secciones que preceden (línea recta descendente; línea recta ascendente; hijos naturales reconocidos), heredarán los parientes colaterales y los cónyuges por el orden que se establece en los artículos siguientes".

No han sufrido alteración alguna los artículos 947 a 951 , ni los 954 y 955 . Fueron suprimidos por la Ley 11/1981, los artículos 952 y 953.

Aunque suprimido, como decimos, es curiosa la vicisitud sufrida por el artículo 952, hasta su definitiva desaparción, y así:

a.- Redacción originaria: "A falta de hermanos y sobrinos hijos de éstos, sean o no de doble vínculo, sucederá en todos los bienes del difunto el cónyuge sobreviviente que no estuviese separado por sentencia firme de divorcio".

b.- Redacción por Ley de 2 de abril de 1958: Es idéntica a la anterior, pero cambiando el inciso final "...que no estuviese separado por sentencia firme de divorcio", por "...que no estuviese separado por sentencia firme de separación personal".

c.- Supresión por la Ley de 13 de mayo de 1981, en cuenta entra en colisión frontal con ella.

B.-Estado de la cuestión tras la Ley 11/1981.

Sistemáticamente procede destacar:

a.- Modificación de la Sección $2^{\mathrm{a}}$ (de la línea recta ascendente), en lo siguiente:

$1^{\circ}$.- Eliminación de toda referencia a legitimidad del parentesco.

20.- Supresión, dada su superfluidad, del inciso final del artículo 935.

3․- Ordenación más sistemática de la materia.

b.- Inversión del orden en el epígrafe encabezador de la sección (antaño $4^{a}$ ), altamente significativo. En efecto, si antes era "De la sucesión de los colaterales y de los cónyuges", es ahora "De la sucesión del cónyuge y de los colaterales"..

c.- Regulación en la sección $3^{\text {a }}$ de la sucesión del cónyuge y de los colaterales, al desaparecer la regulación por aquélla de la sucesión intestada de los hijos naturales reconocidos.

d.- Inicio de la sección en el artículo 943, cuando la anterior partía del 946.

En definitiva, y relativamente a la sucesión abintestato del cónyuge viudo, dispone ahora el Código: 
Artículo 943: "A falta de las personas comprendidas en las dos secciones que preceden (línea recta descendente; línea recta ascendente), herederán el cóyuge y los parientes colaterales por el orden que se establece en los artículos siguientes".

Artículo 944: "En defecto de ascendientes y descendientes, y antes que los colaterales, sucederá en todos los bienes del difunto el cónyuge sobreviviente".

Artículo 945: "No tendrá lugar el llamamiento a que se refiere el artículo anterior si el cónyuge estuviera separado por sentencia firme, o separado de hecho por mutuo acuerdo que conste fehacientemente".

Evidentemente, de ocupar el décimo grado en el orden sucesorio abintestato hasta ponerse en cabeza, la progresión, el avance ha sido absolutamente radical. También es cierto que han debido transcurrir siglos y producirse mutaciones esenciales en la sociedad.

Más que nada a título de curiosidad, valdría la pena recordar una antañona polémica, resumiéndola en unas cuantas líneas.

¿Existe el susfructo vidual en la sucesión intestada? era el título con que Mucius Scaevola encabezaba un trabajo publicado en 1899 en la "Revista de los Tribunales".

Interrogación justificada, a la vista de la redacción originaria del artículo 953 del Código, que disponía: "En el caso de existir hermanos o hijos de hermanos, el viudo o viuda tendrá derecho a percibir en concurrencia con éstos, la parte de herencia en usufructo que le está señalada en el artículo 837". Ergo, y de la interpretación literal del artículo, se desprendía, inconcusa e inexorablemente, la inexistencia del derecho a la cuota vidual usufructuaria en la sucesión intestada, concurriendo con ascendientes y descendientes.

Obviamente, no todos los autores aceptaban la interpretación en su rigurosidad del artículo. Más he aquí que, hábilmente, vino a zanjar la cuestión la Ley de 24 de abril de 1958 con tan sólo añadir al controvertido artículo una simple frase: "la legítima que en todo caso corresponde al viudo o viuda en la sucesión intestada".

CONYUGE HEREDERO Y OBLIGACION DE RESERVAR.

Dos clases de reservas regula el Código, la lineal o troncal y la vidual o binupcial. A ambas nos referimos seguidamente.

A.- La reserva linal o troncal.

Por disposición del artículo 811 del Código Civil: "El ascendiente que heredare de su descendiente bienes que éste hubiese adquirido por título lucrativo de otro ascendiente, o de un hermano, se halla obligado a reservar los que hubiere adquirido por ministerio de la Ley en favor de los parientes que estén dentro del tércer grado y pertenezcan a la línea de donde los bienes proceden".

(Quizá convenga adelantar que nuestro propósito no es ahondar en el contenido del tan discutido y archiinterpretado precepto, sólo lo abordamos, de puntillas, en cuanto ha resultado afectado por la reforma llevada a cabo en sede de sucesiones por la Ley 11/1981).

Aclarado lo anterior, conviene destacar la opinión mantenida al respecto por distintos autores, y así: 
-Afirman Lacruz-Sancho: "A partir de la reforma de 1981, el cónyuge viudo, que tenía un lugar menos favorecido en el Código, pasa por delante de los hermanos del causante, lo cual no es muy justo cuando los bienes de éste son de procedencia familiar, y representa una contradicción con la reserva del artículo 811. ( $\mathrm{Si}$ el viudo hereda directamente nada tiene que reservar, mientras que si recibe los bienes del premuerto a través de un hijo que los heredó de aquél y se los transmite, se produce el supuesto de la reserva" (11).

En opinión de Torres Lana: "...la practicidad del precepto (811) va a verse notablemente reducida en la sucesión abintestato. En ésta, la nueva redacción del articulo 944 implica el sacrificio del principio de troncalidad a beneficio de una concepción nuclear de la familia...En consecuencia, el avance del cónyuge viudo en su posición sucesoria, a costa de los colaterales, disminuye ostensiblemente la frecuencia de la configuración del supuesto de hecho de la reserva troncal". (12).

Con fundamento en la tradición y en la esencia misma de la institución que estudiamos, escribe Albadalejo: "Después de la reforma del Código por la ley de 13 de mayo de 1981, la impresión parece que sería la de no haber duda de que actualmente la reserva del artículo 811 es aplicable cualquiera que sea la filiación matrimonial o no, de los parientes favorecidos de qué se trata... Sin embargo, no por discriminación de filiaciones, sino a base de las razones históricas por las que se introdujo la reserva y por la concepción de la troncalidad en que se funda, es también defendible la opinión de que, en principio, del beneficio del atículo 811 queda excluida aún hoy, la filiación no matrimonial..." (13).

Hace más de un siglo, escribía Alonso Martínez, en relación con los trabajos de la Comisión de Codificación, y concretamente en punto a reserva troncal: "Qué razones pudieron moverla (a la Comisión) a establecer la sucesión lineal, separándose del cauce secular?. Y seguía: "Lo diré en breves frases. Hay un caso, no del todo raro, que subleva el sentimiento de cuantos lo imaginan o lo ven: el hijo mayor de un magnate sucede a su padre en la mitad íntegra de pingües mayorazgos, tocando a sus hermanos un lote modestísimo en la división de la herencia paterna; aquél hijo se casa y fallece al poco tiempo dejando un tierno vástago; la viuda, todavía joven, contrae segundas bodas y tiene la desdicha de perder al hijo del primer matrimonio heredando toda su fortuna con exclusión de la madre y los hermanos de su primer marido. No hay para qué decir que, si hay descendientes del segundo matrimonio, a ellos se transmite en su día la herencia. Por donde resulta el irritante espectáculo de que los vástagos directos del magnate viven en la estrechez y tal vez en la miseria, mientras gozan de su rico patrimonio personas extrañas a su familia y que, por un orden natural, la son profundamente antipáticas. Esta hipótesis se puede realizar y se realiza, aunque por lo general en menor escala, antre propietarios, banqueros e industriales, labradores y comerciantes, sin necesidad de vinculaciones ni títulos nobiliarios". (14).

\section{B.- La reserva vidual.}

Tras la Ley de 13 de mayo de 1981, escasas modificaciones se advierten en los artículos 973 y 978 del Código; en el primero, la adición en el inciso final del párrafo segundo de la remisión -además de al artículo 857 , que ya hacía- al número $2^{\circ}$ del 
artículo 973. En lo que ser refiere al artículo 978, la alteración se reduce a excluir de su número $1^{\circ}$, la referencia a parafernales y dote.

Asimismo en esta línea de adecuación a las nuevas exigencias y realidades sociales, sufre alteración, en esta ocasión más amplia, el artículo 980 que en su redacción anterior a 1981 disponía: "La obligación de reservar impuesta en los anteriores artículos será aplicable al viudo o viuda que aunque no contraiga nuevo matrimonio, tenga en estado de viudez un hijo natural reconocido o declarado judicialmente como tal hijo. Dicha obligación surtirá efecto desde el día del nacimineto de éste.

Redacta la Ley de 1981 el artículo de referencia, de la forma que sigue: "La obligación de reservar impuesta en los anteriores artículos será también aplicable: $1^{\circ}$. Al viudo que durante el matrimonio haya tenido o en estado de vuidez tenga un hijo no matrimonial. $2^{\circ}$. Al viudo que adopte plenamente a otra persona. Se exceptúa el caso del consorte de quien descienden los que serían reservatarios. Dicha obligación de reservar surtirá efecto, respectivamente, desde el nacimiento o la dopción del hijo".

Evidentemente, si la reserva vidual se establece en favor de los hijos y descendientes del cóyuge fallecido, todos los bienes que hubiere recibido de éste o de los hijos de su finado matrimonio, por testamento, sucesión intestada, donación o cualquier otro título lucrativo, o de los parientes del difunto en consideración a éste, es claro que idéntico sentido subyace tanto en el hecho de contraer nuevas nupcias, como en el de tener un hijo en estado de viudez, o, constante matrimonio, de persona distinta del consorte, o en el de adoptar plenamente a una persona.

Evidencia confirmada por el propio artículo cuando, en el supuesto de adopción, no excluye de la reserva al adoptado, si éste fuere hijo del consorte de quien descienden los que serían reservatarios; y no lo excluye, precisamente, porque resulta que él mismo es reservatario.

Descuida el legislador cualquier clase de precisión al redactar los preceptos, así, en el caso que nos ocupa dice que la obligación de reservar surtirá efecto, respectivamente, desde el nacimiento o la adopción del hijo, ¿también desde el nacimiento del hijo no matrimonial habido en estado de casado?. La falta del mínimo de rigor que en ocasiones se aprecia en el legislador de nuestro tiempo conduce al terror pánico a los interpretes y comentaristas del derecho cuando a su conocimiento llega la inquietante noticia de la prevista, iniciada o proyectada corrección, modificación o elaboración de una Ley.

Puntualiza Torres Lana que la reforma no ha tenido en cuenta la concurrencia de dos elementos ajenos al origen y fundamento de la reserva, harto perturbadores. Son ellos: $1^{\circ}$. La existencia de hijos extramatrimoniales del cónyuge premuerto. $2^{\circ}$. La posibilidad de que las segundas nupcias hayan sido contraidas no por fallecimiento del cónyuge, sino como consecuencia de divorcio.

Con referencia al primer elemento señalado, la conclusión a obtener, interpretando en su literalidad el párrafo primero del artículo 108 del Código, sería la de la atribución del carácter de reservatarios única y exclusivamente a los hijos matrimoniales, empero la carga discriminatoria que ello parecería suponer. 
Más, por contra, sí podrían tener carácter de reservatarios los hijos extramatrimoniales de los hijos comunes del matrimonio.

La segunda de las hipótesis barajadas, es decir, que las nuevas nupcias hayan sido contraidas no por razón de fallecimiento sino por divorcio, parece no haber inquietado lo más mínimo al legislador de 1981, que no altera en la reforma ni una como sobre este punto. Despreocupación del legislador que coloca a Torres Lana en situación de plantear la disyuntiva siguiente: o el legislador de 1981 ha querido conservar los presupuestos del régimen anterior, manteniendo sólo para el viudo la obligación de reservar -lo que no le resulta lógico o no ha acometido su modificación por olvido o desconocimiento lamentables.

Ante tal shakesperiano dilema, se decanta Torres Lana -y probablemente acierte- por la segunda posibilidad apuntada. (15).

Opinan, también a este propósito Lacruz-Sancho: "...en la actualidad un evento que no pudo tener en cuenta el legislador de 1889 , el divorcio, disuelve igualmente el matrimonio, y por cierto sin dar lugar a la restitución de lo donado por un esposo al otro, y con mayor razón se impone en él la reserva si el divorciado vuelve a casarse o tiene otros hijos; el mismo conflicto de intereses debe tener la misma solución, que el legislador de 1889 no pudo formular expresamente". (16).

Se pregunta Albadalejo sobre la preponderancia de la reserva torncal a la de la binupcial, apuntando el decantamiento de la opinión más extendida en pro de aquélla, pero añadiendo: "De cualquier modo, a veces la equidad parecería pedir el triunfo de ésta". (17).

\section{De la colación y partición.}

\section{1.- Colación.}

Interesa de ella específicamente, el estudio del artículo 1045 en sus redacciones anterior y con ocasión de la Ley de 13 de mayo de 1981.

\section{A.- Redacción anterior a 1981.}

"No han de traerse a colación y partición las mismas cosas donadas o dadas en dote, sino el valor que tenían al tiempo de la donación o dote, sino el valor que tenían al tiempo de la donación o dote, aunque no se hubiese hecho entonces justiprecio. El aumento o deterioro posterior, y aun su pérdida total, causal o culpable, será a cargo y riesgo o beneficio del donatario".

B.- Redacción por Ley 11/1981.

"No han de traerse a colación y partición las mismas cosas donadas, sino su valor al tiempo en que se evalúen los bienes hereditarios. El aumento o deterioro físico posterior a la donación y aun se pérdida total, casual o culpalble, será a cargo y riesgo o beneficio del donatario".

El contejo de ambas redacciones resulta:

a.- Supresión de la referencia a la dote, régimen matrimonial económico suprimido del Código por la Ley de 1981.

b.- Relativamente al párrafo primero, en la redacción anterior al remitirse al valor de la cosa donada al tiempo de la donación -especialmente cuando hubiera 
transcurrido un largo periodo- constituía una más que posible discriminación que podría llegar a perjudicar gravemente los derechos de los restantes legitimarios; además de la dificultad de apreciación transcurridos, las más de las veces, varios años.

Más realista, la redacción actual permite una más adecuada apreciación y evita cualquier perjuicio, que, también hay que decirlo, pudiera en ocasiones repercutir en contra del donatario.

c.- En cuanto al segundo párrafo, la diferencia existente es la referencia concreta a deterioro físico del bien donado, siendo por lo demás, en ambas redacciones -en cuanto iguales- perfectamente ajustado a razón que revierta en beneficio del donatario el posible aumento del valor, en contrapartida del riesgo que ha de asumir de pérdida o deterioro.

\section{2.- Partición.}

Importante modificación es, sin duda, la efectuada por la Ley de 13 de mayo de 1981 en el artículo 1057 del Código.

Decía éste en su redacción anterior: "El testador pordrá encomendar por actos inter vivos o mortis causa para después de su muerte la simple facultad de hacer la partición a cualquier persona que no sea una de sus herederos. Lo dispuesto en este artículo y en el anterior se observará aunque entre los coherederos haya alguno menor de edad sujeto a tutela; pero el comisario deberá en este caso inventariar los bienes de la herencia, con citación de los coherederos, acreedores y legataios".

Dejándolos invariados en su redacción, incrusta la Ley 11/1981 entre los dos párrafos transcritos del artículo 1057, el siguiente: "No habiendo testamento, contador-partidor en él designado o vacante el cargo, el Juez, a petición de herederos y legararios que representen, al menos, el 50 por 100 del haber hereditario, y con citación de los demás interesados si su domicilio fuere conocido, podrá nombrar un contador-partidor dativo, según las reglas que la Ley de Enjuiciamiento Civil establece para la designación de peritos. La partición así realizada requerirá aprobación judicial, salvo confirmación expresa de todos lo herederos y legatarios".

Exige el párrafo en estudio una serie de reflexiones que podrían iniciarse por el desglose de cada uno de sus requisitos, y así:

$1^{\circ}$.- Inexistencia de testamento; aún existiendo que no se designe en él contador-partidor alguno; que, incluso habiéndose designado, el cargo estuviere vacante por no aceptación o imposibilidad del designado o por cualquier otra causa.

$2^{\mathrm{o}}$.- Que por un número de herederos y legatarios que representen, al menos, el 50 por 100 del haber hereditario, se solicite del Juez el nombramiento de contadorpartidor (llamado, para este caso, dativo).

3 .- Recibida por el Juez la petición, y previamente al nombramiento del solicitado contador-partidor, procederá a citar a los demás interesados si fuere conocido su domicilio.

¿Procederá, caso de no ser conocido el domicilio de alguno de los interesados, su citación, por edictos, como es práctica habitual? La contestación parece ser afir- 
mativa; la citación ha de llevarse a efecto, en cada caso, por el medio que la circunstancia determine.

4.- A tenor del artículo, no es menester más que la citación de los interesados no peticionarios, pues, comparezcan o no, el Juez procederá al nombramiento de contador-partidor, ateniéndose a las reglas que para la designación de peritos establece la Ley procesal civil.

A este propósito cabría apostillar: a) Tratándose de sucesiones la remisión podría entenderse a los artículos 1070, 1071 y 1073 de la Ley procesal. b) Sin embargo, del tenor del artículo 1057, la remisión no deja duda lo es a los artículos 610 y siguientes de dicha Ley. Pero, aceptada esa solución, tampoco es correcta la inteligencia de la aplicación de las reglas establecidas en meritados artículos, siendo de necesidad la exclusión de la mayoría de ellos por inaplicables, y sólo de utilidad los que encajen en las reflexiones que siguen:

a.- La mera petición dirigida al Juez faculta a éste, a tenor del artículo en cuestión, para designar contador-partidor a la persona que tenga por conveniente, sin necesidad de previa comparecencia ni intervención de las partes. Postura sostenible pero harto discutible, haciendo entrar en colisión el artículo 1057 y los relativos a comparecencia de las partes para insaculación de peritos.

b.- No parece quepa oposición al nombramiento del contador-partidor, por los no peticionarios citados, en tanto discutible la necesidad de la comparecencia prevista en el artículo 614 de la Ley procesal. Si bien podrán hacer uso posterior de su derecho.

c.- Por aplicación analógica del artículo 1070 -y pues que con relación a los peritos establece la Ley que estén en posesión de tales en la ciencia o arte a que pertenezca el punto sobre el que deben dictaminar- la persona designado por el Juez contador-partidor habrá de ser Letrado.

5.- Aceptado el cargo, el contador designado procederá a la redacción del cuaderno particional, que deberá ser aprobado por el Juez salvo confirmación expresa de todos los herederos y legatarios.

No resultaría aventurado opinar que el párrafo estudiado del artículo $1057 \mathrm{se}$ introdujo por el legislador como una posibilidad más de evitar el recurso al artículo 1059 por algún heredero.

De esta forma, prevista normativamente la partición hecha por el propio testador; la realizada por el contador-partidor designado por aquél; y la que directamente llevaran a efecto los propios herederos, solo quedaba un resquicio a la temeridad de algún heredero intransigente que, oponiendose a la opinión uniforme de los restantes, podía, sin embargo, entablar el juicio de testamentaría. Y este resquicio, este portillo, es el que pretende ocluir el párrafo comentado; introduciendo, además, una escrupulosa matización en respuesta al caso concreto, así: inexigencia de aprobación judicial cuando exista conformidad expresa de todos los herederos y legatarios; necesidad en otro caso, de dicha aprobación.

Escribe Torres Lana: "La intervención judicial supone sólo un control de la legalidad e imparcialidad del proceso que se inicia con el nombramiento del conta- 
dor-partidor y culmina con la adjudicación." y añade "...el contenido del cargo, en cuanto a sus funciones, deberes y plazo para desempeñarlo, parece ser idéntico al del contador-partidor testamentario". (18).

Para Lacruz-Sancho: "Será Juez competente para el nombramiento de contador dativo el que lo sea para la testamentaría. La arbitración no tiene valor definitivo, sino que requiere aprobación judicial: el artículo 1057 no limita los extremos a que puede extenderse, a tal efecto, el examen del Juez, quien, por tanto, podrá negar su refrendo, no sólo por falta de aplicación de alguna norma legal o por defectos formales, sino también por lesión de un partícipe, o inexacta valoración de un bien, etc. En cualquier caso tal aprobación no convierte a la partición en judicial". (19).

En opinión de Albadalejo: "Con este nuevo procedimiento no hay necesidad de promover alguno de los engorrosos juicios universales... para llegar en definitiva a una partición consentida por otros, ni de plantear un largo y costoso juicio declarativo ordinario para, si alguno se opone a tal partición, conseguir un reparto de los bienes hereditarios que vincule a los conformes y a los disconformes". (20).

Procede añadir a lo referido:

A.- A tenor del párrafo segundo del artículo 841, también el contadro-partidor dativo goza de la facultad de adjudicar todos los bienes herecitarios o parte de ellos a uno de los herederos, mandando se pague en matálico la porción correspondiente a los restantes herederos.

B.- Si bien no se habla de remuneración al contador-partidor dativo, prosperando la tesis de que éste haya de ser Abogado, es innegable la obligatoriedad de satisfacción de sus honorarios.

C.- Empero referidos a contador-partidor nombado por el testador, son de aplicación al dativo las sentencias del Tribunal Supremo siguiendo la doctrina marcada por la de 12 de diciembre de 1927, que establecía: "La partición hereditaria formalizada por el comisario nombrado causa estado y no puede ser impugnada en vía gubernativa y ha de producir, mientras los Tribunales no declaren lo contrario, los efectos y consecuencias que lógicamente se deriven de los términos en que se halle redactada, pero los herederos que se crean perjudicados por la interpretación dada a las cláusulas testamentarias, por la valoración del caudal relicto, o por cualquier otra circunstancia, pueden atacar la partición o solicitar su rescisión".

De la modificación del artículo 1060.

También objeto de la atención del legislador de 1981, disponía en su anterior redacción:

"Cuando los menores de edad estén sometidos a la patria potestad y representados en la partición por el padre o, en su caso, por la madre, no será necesario la intervención no la aprobación judicial".

Manifiesta en su redacción actual:

"Cuando los menores o incapacitados estén legalmente representados en la partición, no será necesaria la intervención ni la aprobación judicial".

En relación con la anterior redacción, es de destacar de la nueva:

$1^{\circ}$.- Referencia no sólo a menores sino también a incapacitados. 
$2^{\circ}$.- La representación legal, caso de patria potestad, corresponde en la actualidad, y conjuntamente, al padre y a la madre. Los incapacitados pueden estar sujetos a patria potestad prorrogada.

3o.- Menores e incapacitados pueden estar sujetos a tutela, siendo entonces el tutor su representante legal. (Tras la reforma de las instituciones tutelares en 1983, conviene reseñar lo siguiente: Artículo 271: "El tutor necesitará autorización judicial: ...4ํ.- Para realizar la partición de la herencia o la división de una cosa común, las cuales, una vez practicadas, requerirán, además, la aprobación judicial..." y el artículo 272: "También necesitará el tutor autorización judicial: 1ํ.- Para aceptar sin beneficio de inventario cualquier herencia o para repudiar ésta o las liberalidades...").

Se preguntaba Manresa: "¿Cuándo será necesaria y cuando no la aprobación judicial de las particiones de herencia, según el estado actual de nuestro derecho?, y continuaba:

Aun mediando menores o incapacitados o ausentes, no es exigible dicha aprobación en los casos siguientes:

$1^{\circ}$.- Cuando la partición hubiese sido practicada por el mismo testador.

$2^{\circ}$.- Cuando se haya hecho por persona a quien el testador hubiese encomendado esta facultad, siempre que no sea uno de los herederos e inventariando los bienes, con citación de dichos herederos, acreedores y legatarios.

$3^{\circ}$.- Cuando los menores de edad estén sometidos a la patria potestad y representados en la partición por su padre o su madre, siempre que éstos no tengan en la herencia interés en oposición con los del hijo menor.

$4^{\circ}$.- En las particiones de herencia practicadas antes de la Ley de Enjuiciamiento Civil de 1855.

5o.- Cuando tratándose de herederos voluntarios, el testador hubiera dispuesto que se hiciesen las particiones sin el requisito de la aprobación judicial.

Sigue Manresa: habría que añadir otro caso, el de tratarse de personas sujetas a tutela, por estimarse que en tal caso correspondería la aprobación al consejo de familia. Pero aún en este caso, tal aprobación debería sustituirse por la judicial cuando todos los individuos del consejo o la mayoría de ellos resultasen incompatibles..." (21).

En rigor el problema nace de la colisión entre el artículo 1060 del Código Civil y el 1049 de la Ley de Enjuiciamiento Civil, que establece: "Las liquidaciones y particiones de herencia hechas extrajudicialmente, aunque lo hayan sido por contadores nombrados por el testador, deberán presentarse a la aprobación judicial siempre que tenga interés en ellas como heredero o legarario de parte alícuota algún menor incapacitado o ausente cuyo paradero se ignore". Pero como el propio Manresa señala, el artículo 1049 de la Ley procesal se halla modificado en el Código por los artículos 1057 y 1060. (22). 


\section{ACLARACION FINAL}

Obviamente habrá advertido el lector la omisión de referencia a algunos de los artículos también afectados por la Ley de 13 de mayo de 1981, como, por ejemplo, los números $741,761,692,962,855,857$, etc., la razón de ello respondió al entendimiento de que las modificaciones introducidas consistieron en meros retoques adecuatorios en la mayoría de los casos, o supresión de algún matiz que, en general, no afectaba esencialmente a su contenido.

Y así, en ello como en cualquier otro punto que hubiera sido omitido en este trabajo, vino también a incidir el compromiso de enviarlo para su publicación en la Revista Anales de la Facultad de Derecho de esta Universidad, que, en consideración a mi persona que desde aquí agradezco sinceramente, amplió en algunos días el término de entrega de los originales.

\section{NOTAS BIBLIOGRAFICAS}

(1).- Volterra. (Anotado y puesto al día por Daza Martínez.- Pg. 779.- Madrid, 1988.

(2).- Edición facsimil del B.O.E.

(3).- Lacruz Berdejo-Sancho Rebullida.- Elementos de Derecho Civil. V.- Derecho de Sucesiones.- Barcelona, 1982. Pg. 561.

(4).- Díez-Picazo-Gullón Ballesteros.- Sistema de Derecho Civil. V.- Derecho de familia y sucesiones.- Pg. 641.- Madrid, 1982.

(5).- Lacruz-Sancho.- Ibid.

(6).- Torres Lana.- "Reforma de familia y sucesión mortis causa". en Documentación Jurídica.- Núms. 33 a 36. Enero-Diciembre. V.I., 1982.

(7).- Cf. Castán Tobeñas.- Derecho Civil español común y foral.- T. 6․- V. 3ำ .- Madrid, 1971.

(8).- Cf. Lacruz-Sancho.- Op. Cit. Pg. 562.

(9).- Cf. Torres Lana.- Op. Cit, Pgs. 335-336.

(10).- Df.- albaladejo.- Curso de Derecho Civil. V.- Derecho de Sucesiones.- Barcelona, 1982.- Pgs. 385 a 387 .-

(11).- Lacruz-Sancho.- Op. Cit. Pgs. 561-2.

(12).- Cf.- Torres Lana.- Op. Cit. Pg. 339.

(13).- Albaladejo.- Op. Cit. Pg. 398.

(14).- Alonso Marínez.- El Código Civil en sus relaciones con las legislaciones forales.Editorial Plus-Ultra. Madrid, 1949. Pgs. 185-186.

(15).- Cf. Torres Lana- Op. Cit. Pg. 339.

(16).- Lacruz-Sancho.- Op. Cit.- Pg. 572.

(17).- Albaladejo.- Op. Cit.- Pg. 397.

(18).- Torres Lana.- Op. Cit.- Pgs. 333-334

(19).- Lacruz-Sancho.- Op. Cit.- Pg. 147.

(20).- Albaladejo.- Op. Cit.- Edición, 1991.- Pg. 162.

(21).- Manresa Navarro.- Comentarios al Código Civil.- T.VII. Pgs. 739-740.

(22).- Manresa.- Op. Cit.- Pg. 735. 